\title{
One-Pot Synthesis of Aromatic Hydroxyketones under Microwave Irradiation and Solvent-Free Conditions
}

\author{
Yuqing Cao (Corresponding author) \\ College of Pharmacy, Hebei University \\ Baoding 071002, Hebei, China \\ E-mail:pharm_hbu@yahoo.com \\ Fangrui Song \\ College of Pharmacy, Hebei University \\ Baoding 071002, Hebei, China \\ E-mail: fangrui102@163.com \\ Liya Xu, Dingxiang Du, Xiaojun Yang \& Xiangtao Xu \\ College of Pharmacy, Hebei University \\ Baoding 071002, Hebei, China
}

\begin{abstract}
An efficient one-pot synthesis of aromatic hydroxyketones with carboxylic acids as acylating agents without solvent under microwave irradiation was reported. The reaction time was only 1-5 min. Besides, this method has a feature of high yields, low cost, easy manipulation and less pollution.
\end{abstract}

Keywords: One-pot synthesis, Microwave irradiation, Aromatic hydroxyketones, Carboxylic acids, Solvent-free

\section{Introduction}

Aromatic hydroxyketones are valuble intermediates in the synthesis of pharmaceuticals (Szmant, H. 1989), perfumery (Naeimi, H. et.al 2006), acetophenone resins (Heitling, E. et.al 2004), etc. The classic synthesis commonly involves two steps, esterification of phenols and fries rearrangement which is an intermolecular Friedel-Crafts acylation of phenolic ester (Kozhevnikova, E. F. et.al 2004,Vogt, A. et.al 1995). The disadvantages associated with classic procedures include the use of toxic acid chlorides or acid anhydrates as acylating agents (Rupinder, K. L. et.al 2006, Ludwigshafen, J. M. et.al 1985) and aluminum trichloride as Lewis acids (Miller, E. et.al 1943) and an excess amount of reagents for separation of phenolic ester, which entains environment pollution and tedious workup. Recently, zeolite H-beta (Hoefnagel, A. J. 1993) and montmorillonite clay (Bolognini, M. et.al 2004) are reported to be used as catalysts for synthesis of aromatic hydroxyketones, but these catalysts both need special treatment before use such as calcination at a high temperature. Moreover, the whole reaction process normally requires long reflux times at oil bath. The drawbacks as above described have prompted considerable researches into the development of a new method which is low cost, easy manipulation and less pollution.

Microwave irradiation as a new technology has been widely used in various organic reactions, such as substitution (Mojtahedi, M. M. et.al 1999), addition (Mojtahedi, M. M. et.al 1999), dehydration (Bandgar, B. P. et.al 1999), rearrangement (Khadikar, B. M. et.al 1999) and redox (Palombi, L. et.al 1997). Solvent-free could avoid the use of auxiliary reagents that may be toxic or flammable, and also simplify the follow-up operation. The synthesis without solvent under microwave irradiation has been of growing interest as an efficient, economic and, clean procedure (Pasha, M. A. et.al 2007, Gopalakrishnan, M. et.al 2005). Carboxylic acids are common precursors of acid chlorides and anhydrides and their reactions produced water as the only by-product (Naeimi, H. et.al 2006). From an environment point of view, the aromatic acylation with carboxylic acids has also attracted interest.

In this paper, the mixture of phenols, carboxylic acids, phosphoric acid and phosphorus pentoxide $\left(85 \% \mathrm{H}_{3} \mathrm{PO}_{4} / \mathrm{P}_{2} \mathrm{O}_{5}\right)$ were irradiated in a microwave oven, the target products were obtained by one-pot. 


\section{Experimental}

\subsection{General}

All reactions were performed in a modified commercial domestic microwave oven (Midea PJ21C-BF) which was equipped with a reflux device. TLC was used to monitor the reaction process. TLC was GF254 thin- layer chromatography with petroleum ether/ethyl acetate $(4: 1 \mathrm{v} / \mathrm{v})$ used as eluent. Melting points were determined on a microscopy apparatus (SGW X-4). IR spectra were recorded on a Bio-Rad FTS-40 spectrometer (KBr). All the liquid parent materials are fresh distilled. The products were characterized by comparison of their melting points and boiling points with the literature values.

\subsection{General procedure for the preparation of o-/p- Hydroxyacetophenone}

A mixture of phenol $(9.4 \mathrm{~g})$, acetic acid $(7.0 \mathrm{~mL}), 85 \% \mathrm{H}_{3} \mathrm{PO}_{4}(2 \mathrm{~mL})$ and $\mathrm{P}_{2} \mathrm{O}_{5}(0.9 \mathrm{~g})$ was irradiated at middle power $(231 \mathrm{~W})$ in a $50 \mathrm{~mL}$ one-necked, round-bottomed flask equipped with a reflux device which was placed into a $200 \mathrm{~mL}$ beaker. The progress of the reaction was monitored by TLC. Upon completion, the products were poured into water $(200 \mathrm{~mL})$. Extracted the acylation products from water with ether. The water layer was rejected. Distilled the ether layer to remove ether. The $p$-hydroxyacetophenone ( $p$-HAP) $9.8 \mathrm{~g}$ (72\%yield) was obtained by filtration and purification. m.p.108-109 ${ }^{\circ} \mathrm{C}$.(lit m.p. $109{ }^{\circ} \mathrm{C}$ ); The organic phase detached from the filtration was distilled. Collecting the distillation of $215-218^{\circ} \mathrm{C}$ to obtain the $o$-hydroxyacetophenone (o-HAP) $2.4 \mathrm{~g}$ (18\%yield). (lit b.p. 213 $\left.{ }^{\circ} \mathrm{C}\right)$. The IR spectra of the products were accordant with the standard IR spectra respectively.

\section{Results and Discussion}

Carboxylic acids are less reactive than acid chlorides or acid anhydrates, in the present case, however, the high charge density of the aromatic ring in phenols makes carboxylic acids the best candidate for the electrophilic reaction. Microwave irradiation promoted this electrophilic acylation, because the water as its only by-product was easily removed under microwave irradiation.

\subsection{The catalytic medium for the preparation of aromatic hydroxyketones}

In our study, the mixture of phosphoric acid and phosphorus pentoxide $\left(85 \% \mathrm{H}_{3} \mathrm{PO}_{4} / \mathrm{P}_{2} \mathrm{O}_{5}\right)$ was choosen as a catalytic medium which was mild, cheap and, easy to be got. More importantly, phosphoric acid and phosphorus pentoxide both were easily washed away by water. The weight ratio of $85 \% \mathrm{H}_{3} \mathrm{PO}_{4}$ to $\mathrm{P}_{2} \mathrm{O}_{5}$ was $4: 1 . \mathrm{P}_{2} \mathrm{O}_{5}$ mainly played a role of dehydrating agent, since the use of $\mathrm{P}_{2} \mathrm{O}_{5}$ alone always failed to promote acylation. Phosphoric acid was crucial to the catalytic effectiveness. As a liquid catalyst, it not only promoted acylation but also supplied convenience for the mixing of solids reactants. This catalytic medium has an efficiency under microwave irradiation. Large amount of the catalyst might make reactants darked and parched like the phenomenon reported in previous literature in short times and low power (Kozhevnikova, E. F. et.al 2004), we guessed it may result from the polymerization of olefine ketone which is easily produced under excessive catalyst. The optimal molar ratio of $\mathrm{H}_{3} \mathrm{PO}_{4}$ to aromatic substrate is $0.3: 1$.

With carboxylic acids as acylating agents, this "protonic-acid catalytic method" is a preferred one because of its simplicity. There is no large amount of metal salts formed after reaction like Lewis acids. Furthermore, the usage amount of catalyst was largely reduced. This not only saved the production cost, but also decreased the pollution to environment.

\subsection{Effect of power and reaction time on yield of products}

The power and reaction time both have an obvious effect on yield of products. Taking phenol to react with acetic acid for example, as is shown in table 1, the yield was higher at $231 \mathrm{~W}$ than that at $119 \mathrm{~W}$, however, when the power was $385 \mathrm{~W}$ or upwards, lots of side products formed due to the oxidation of phenols and other side reactions. Microwave irradiation can produce lots of heat in short time, so the temperature is not easy to control if the reaction time is too long. The optional microwave irradiation power was $231 \mathrm{~W}$ and the reaction time was $2 \mathrm{~min}$.

\subsection{Acylation of various phenols with acetic acid}

Various phenols were treated with acetic acid along with a catalytic amount of catalyst under microwave irradiation and solvent-free conditions. As shown in table 2, most phenols afforded their corresponding aromatic hydroxyketones in excellent yields by one-pot and the reaction time was only 1-3min which was greatly reduced compared with long reflux times by conventional heating. The phenols with electron-donating groups such as $-\mathrm{OCH}_{3}$ were more reactive than those with electron-withdrawing groups such as $-\mathrm{Cl}$, that mainly because the electron-donating groups could increase the electron density of aromatic ring which caused the reaction easier. When a $-\mathrm{NO}_{2}$ on the aromatic ring (entry9), the reaction did not afford the corresponding hydroxyketone. Most phenols could obtain their ortho-acylated products in high yields. Due to the poor regioselectivity of phenol (entry1) 
and catethol (entry2), the acylation result was a mixture of ortho-acylated and para-acylated products. However, the regioselectivity of phenol and catethol was enhanced and the para-isomer was obtained in high yields under this reaction conditions. In addition, the naphthols and heteroaromatic compound substituted with hydroxyl group also can react in excellent yields.

\subsection{Acylation of phenol with various carboxylic acids}

In continuation, the acylation of phenol with propionic acid, butanoic acid, valeric acid, succinic acid and benzoic acid in the presence of catalyst without solvent under microwave irradiation was tried, respectively. These reactions also produced para-acylated compounds in high yields and in short times except succinic acid. Succinic acid was a binary acid, because of the high charge density of phenol, the diphenyl succinate was easily formed under this reaction conditions. The obtained results of other carboxylic acids were shown in table 3. Thereinto, $p$-hydroxypropiophenone (entry1) is a key intermediate for preparation of ritodrine which is an agonist for $\beta_{2}$ acceptor of adrenalin. Compared with the previous method (Rupinder, K. L. et.al 2006, Ludwigshafen, J. M. et.al 1985, Miller, E. et.al 1943), this new method only took $2 \mathrm{~min}$ to finish the reaction with yield of $79 \%$. In an environmentally benign, it is more favourable for large-scale chemical industry production. In addition, microwave irradiation has greatly promoted the smooth progress of the reaction between phenol and solid carboxylic acids such as benzoic acid (entry4) without solvent. Easy sublimation of benzoic acid at $100^{\circ} \mathrm{C}$ made the yield lower than that of aliphatic carboxylic acids in table 3 .

\section{Conclusions}

In this paper, we reported an efficient one-pot synthesis of aromatic hydroxyketones with carboxylic acids as acylating agents without solvent under microwave irradiation. In competition with the previous method, it not only simplies the procedure but also diminishes the waste problem of the aforementioned known reactions with metal chlorides. Besides, the reaction time was greatly reduced, from many hours to 1-5 $\mathrm{min}$.

\section{References}

Bandgar, B. P., Sadavarte, V. S., \& Sabu, K. R. (1999). Microwave activation in organic synthsis: Natural Indian Clay, EPICR EPZGR EPZIOR as novel heterogeneous catalysis for rapid synthesis of nitriles from aldoximes in absence of solvent. Synthetic Communications, 29, 3409-3413.

Bolognini, M., Cavani, F., \& Cimini, M. (2004). An environmentally friendly synthesis of 2,4-dihydroxybenzophenone by the single-step O-mono-benzoylation of 1,3-dihydroxybenzene (resorcinol) and Fries rearrangement of intermediate resorcinol monobenzoate: the activity of acid-treated montmorillonite clay catalysis. Comptes Rendus Chimie, 7, 143-150.

Gopalakrishnan, M., Sureshkumar, P., Kanagarajan, V., \& Thanusu, J. (2005). Aluminium metal power (atomized) catalyzed Friedel-Crafts acylation in solvent-free conditions: A facile and rapid synthesis of aryl ketones under microwave irradiation. Cataysisl Communications, 6, 753-756.

Heitling, E., Roessner, F., \& Van Steen, E. (2004). Origin of catalyst deactivation in fries rearrangement of phenyl acetate over zeolite H-Beta. Journal of Molecular Catalysis A: Chemical, 216, 61-65.

Hoefnagel, A. J. (1993). Direct Fries reaction of resorcinol with benzoic acids catalyzed by zeolite H-beta. Applied Catalysis A: General, 97, 87-102.

Khadikar, B. M., \& Madyar, V. R. (1999). Fries rearrangement at atmospheric pressure using microwave irradiation. Synthetic Communications, 29, 1195-1200.

Kozhevnikova, E. F., Raficc, E., \& Kozhevnikov, I. V. (2004). Fries rearrangement of arylesters catalysed by heteropoly acid catalyst regeneration and reuse. Applied Catalysis A: General, 260, 25.

Kozhevnikova, E. F., Raficc, E., \& Kozhevnikov, I. V. (2004). Fries rearrangement of arylesters catalysed by heteropoly acid catalyst regeneration and reuse. Applied Catalysis A: General, 260, 25.

Ludwigshafen, J. M., Mutterstadt, W. W., \& Ludwigshafen, W. K. (1985). Preparation of o-acylphenols and p-acylphenols, US, 4508924.

Miller, E., \& Hartung, W. H. (1943). O-propiophenol and p-propiophenol. Organic Synthesis, 2, 543-545.

Mojtahedi, M. M., Saidi, M. R., \& Bolourtchian, M. (1999). A novel method for synthesis of disubstituted ureas and thioureas under microwave irradiation. Journal of Chemical Research, 710-711.

Mojtahedi, M. M., Saidi, M. R., \& Bolourtchian, M. (1999). Microwave-assisted aminolysis of epoxies under solvent-free conditions catalyzed by montmorillonite clay. Journal of Chemical Research, 128-129. 
Naeimi, H., \& Moradi, L. (2006). Efficient and mild synthesis of ortho-hydroxyaryl ketones catalyzed by zinc chloride under solvent-free condition and microwave irradiation. Catalysis Communication, 7, 1067-1071.

Naeimi, H., \& Moradi, L. (2006). Facile, convenient and regioselective direct ortho-acylation of phenols and naphtols catalyzed by Lewis acids under free solvent and microwave conditions. Journal of Molecular Catalysis A: Chemical, 256, 242-246.

Palombi, L., Bonadies, F., \& Scettri, A. (1997). Microwave-assisted oxidation of saturated and unsaturated alcohols with t-butyl hydroperoxide and zeolites. Tetrahedron, 53, 15867-15876.

Pasha, M. A., Manjula, K., \& Jayaskankara, V. P. (2007). Antimony catalyzed simple, efficient and solvent-free Friedel-Crafts acylation of aromatics under microwave irradiation. Journal of Saudi Chemistry Society, 11, 327-330.

Rupinder, K. L., Sachin, D., \& Caroline, P. O. (2006). Synthesis, biochemical evaluation and rationalization of the inhibitory activity of a series of 4-hydroxyphenyl ketones as potential inhibitors of 17ß-hydroxysteroid dehydrogenase type 3 (17ß-HSD3). Bioorganic and Medicinal Chemistry Letters, 16, 4519-4522.

Szmant, H. (1989). Organic building blocks for the chemical industry. Wiley. NewYork: pp. 503.

Vogt, A., Kouwenhoven, H. W., \& Prins, R. (1995). Fries rearrangement over zeolitic catalysis. Applied Catalysis A: General, 123, 37-39.

$$
\begin{gathered}
\text { ArOH } \frac{\text { Carboxylic acids }}{85 \% \mathrm{H}_{3} \mathrm{PO}_{4} / \mathrm{P}_{2} \mathrm{O}_{5}, \mathrm{MW}} o-\mathrm{Ar}(\mathrm{OH}) \mathrm{COR}+p \text { - } \mathrm{Ar}(\mathrm{OH}) \mathrm{COR} \\
\mathrm{R}=-\mathrm{CH}_{3},-\mathrm{CH}_{2} \mathrm{CH}_{3},-\mathrm{CH}_{2} \mathrm{CH}_{2} \mathrm{CH}_{3},-\mathrm{CH}_{2} \mathrm{CH}_{2} \mathrm{CH}_{2} \mathrm{CH}_{3},-\mathrm{Ph}
\end{gathered}
$$

Scheme 1. Friedel-Crafts acylation between phenols and carboxylic acids

Table 1. Effect of the power and reaction time on yield of aromatic ketones

\begin{tabular}{|c|c|c|c|c|c|}
\hline $\begin{array}{c}\text { Power } \\
(\mathrm{W})\end{array}$ & $\begin{array}{c}\text { Time } \\
(\mathrm{min})\end{array}$ & $\begin{array}{c}\text { Yield } \\
(\%)\end{array}$ & $\begin{array}{c}\text { Power } \\
(\mathrm{W})\end{array}$ & $\begin{array}{c}\text { Time } \\
(\mathrm{min})\end{array}$ & $\begin{array}{c}\text { Yield } \\
(\%)\end{array}$ \\
\hline 119 & 5 & 79 & 385 & 1 & 75 \\
\hline 231 & 1 & 72 & 385 & 2 & 83 \\
\hline 231 & 3 & 90 & 539 & 1 & 70 \\
\hline 231 & 5 & 87 & 700 & $30 \mathrm{~s}$ & 68 \\
\hline
\end{tabular}


Table 2. Acylation of phenols with acetic acid to aromatic hydroxyketones

\begin{tabular}{|c|c|c|c|c|c|c|}
\hline \multirow{2}{*}{ Entry } & \multirow{2}{*}{ Substrate } & \multirow{2}{*}{ Product } & \multirow{2}{*}{$\begin{array}{l}\text { Time } \\
(\mathrm{min})\end{array}$} & \multirow{2}{*}{$\begin{array}{c}\text { Power } \\
\text { (W) }\end{array}$} & \multirow{2}{*}{$\begin{array}{c}\text { Yield } \\
(\%)\end{array}$} & M.p/b.p $\left({ }^{\circ} \mathrm{C}\right)$ \\
\hline & & & & & & Found/Reported ${ }^{[\mathrm{c}, \mathrm{d}]}$ \\
\hline \multirow{2}{*}{1} & & & \multirow{2}{*}{2} & \multirow{2}{*}{231} & \multirow{2}{*}{90} & $\mathrm{Liq} / 213^{\mathrm{a}}$ \\
\hline & & & & & & 108-109/109 \\
\hline \multirow{2}{*}{2} & & & \multirow{2}{*}{2} & \multirow{2}{*}{231} & \multirow{2}{*}{89} & 96-97/97-98 \\
\hline & & & & & & $118-119 / 119-121$ \\
\hline 3 & & & 2 & 231 & 87 & 143-145/144-146 \\
\hline 4 & & & 2 & 231 & 89 & $203-205 / 204-206$ \\
\hline 5 & & & 1 & 231 & 95 & $48-49 / 47-50$ \\
\hline 6 & & & 3 & 231 & 87 & $43-44 / 42-44$ \\
\hline 7 & & & 2 & 231 & 90 & $\operatorname{Lip} / 245^{\mathrm{a}}$ \\
\hline 8 & & & 2 & 385 & 72 & $52-54 / 54-56$ \\
\hline 9 & & & 4 & 385 & 0 & $\square^{\mathrm{b}}$ \\
\hline 10 & & & 3 & 119 & 72 & $98-100 / 98$ \\
\hline 11 & & & 3 & 119 & 70 & $169-170 / 171$ \\
\hline 12 & & & 2 & 119 & 75 & $139-140 / 140-142$ \\
\hline
\end{tabular}


${ }^{\text {a }}$ boiling points were determined.

$\mathrm{b}$ “____ represents no corresponding hydroxyketone obtained.

${ }^{c}$ Adrich catalog handbook of fine chemicals, 1996-1997.

${ }^{\mathrm{d}}$ melting or boiling points from Chemical Abstracts

Table 3. Acylation of phenol with various carboxylic acids to aromatic hydroxyketones

\begin{tabular}{|c|c|c|c|c|c|c|}
\hline \multirow{2}{*}{ Entry } & \multirow{2}{*}{ Substrate } & \multirow{2}{*}{ Product } & \multirow{2}{*}{$\begin{array}{l}\text { Time } \\
\text { (min) }\end{array}$} & \multirow{2}{*}{$\begin{array}{c}\text { Power } \\
(\mathrm{W})\end{array}$} & \multirow{2}{*}{$\begin{array}{l}\text { Yield } \\
(\%)\end{array}$} & M.p/b.p $\left({ }^{\circ} \mathrm{C}\right)$ \\
\hline & & & & & & Found/Reported \\
\hline 1 & $\mathrm{COOH}$ & & 2 & 231 & 79 & $89-90 / 91^{[8]}$ \\
\hline 2 & $\mathrm{OO}$ & & 3 & 231 & 81 & $146-147 / 148^{a}$ \\
\hline 3 & $\mathrm{CO}$ & & 3 & 231 & 83 & $59-60 / 60-62^{a}$ \\
\hline 4 & & & 5 & 385 & 60 & $\begin{array}{c}130-132 / 132-135 \\
\text { a }\end{array}$ \\
\hline
\end{tabular}

${ }^{a}$ Adrich catalog handbook of fine chemicals, 1996-1997. 